\title{
Sustainable Industry 4.0 Wireless Networks, Machine Learning Algorithms, and Internet of Things-based Real-Time Production Logistics in Digital Twin- driven Smart Manufacturing
}

\author{
Elvira Nica ${ }^{1}$, Gheorghe H. Popescu ${ }^{2}$, and George Lăzăroiu ${ }^{3 *}$ \\ ${ }^{1}$ The Bucharest University of Economic Studies, Department of Economics, Piața Romană 6, 010374, \\ Bucharest, Romania \\ 2 "Dimitrie Cantemir" Christian University, Department of Economics, Splaiul Unirii 176, 040042, \\ Bucharest, Romania \\ ${ }^{3}$ Spiru Haret University, Department of Economics, Fabricii 46G, 060821, Bucharest, Romania
}

\begin{abstract}
Research background: The aim of this paper is to synthesize and analyze existing evidence on artificial intelligence-based decision-making algorithms, industrial big data, and Internet of Things sensing networks in digital twin-driven smart manufacturing.

Purpose of the article: Using and replicating data from Altair, Catapult, Deloitte, DHL, GAVS, PwC, and ZDNet we performed analyses and made estimates regarding cyber-physical system-based real-time monitoring, product decision-making information systems, and artificial intelligence data-driven Internet of Things systems in digital twin-based cyber-physical production systems.

Methods: From the completed surveys, we calculated descriptive statistics of compiled data when appropriate. The data was weighted in a multistep process that accounts for multiple stages of sampling and nonresponse that occur at different points in the survey process. The precision of the online polls was measured using a Bayesian credibility interval. To ensure highquality data, data quality checks were performed to identify any respondents showing clear patterns of satisficing. Test data was populated and analyzed in SPSS to ensure the logic and randomizations were working as intended before launching the survey. An Internet-based survey software program was utilized for the delivery and collection of responses. The sample weighting was accomplished using an iterative proportional fitting process that simultaneously balanced the distributions of all variables. The interviews were conducted online and data were weighted by five variables (age, race/ethnicity, gender, education, and geographic region) using the Census Bureau's American Community Survey to reflect reliably and accurately the demographic composition of the United States. Confirmatory
\end{abstract}

* Corresponding author: phd_lazaroiu@yahoo.com 
factor analysis was employed to test for the reliability and validity of measurement instruments.

Findings \& Value added: The way Internet of Things-based decision support systems, artificial intelligence-driven big data analytics, and robotic wireless sensor networks configure digital twin-driven smart manufacturing and cyber-physical production systems in sustainable Industry 4.0.

Keywords: digital twin; smart manufacturing; industrial big data; Internet of Things; smart manufacturing

JEL Classification: E24; J21; J54; J64

\section{Introduction}

Digital twin and data-driven manufacturing processes can enable the development of an autonomous factory setting (Scott et al., 2020) with full-scale operational concreteness and adjustability. Networking distributed digital twins between shop floors enables companies to articulate virtually connected manufacturing systems. ( $\mathrm{Lu}$ et al., 2020) The swift advancement of cutting-edge generation of big data technologies enables the rise of cyberphysical production systems that are pivotal in identifying smart manufacturing solutions. (Liu et al., 2020a) Digital twins provide technical performance at the kind and instance phases of a production unit. (Park et al., 2020) Among various degrees of smartness and networking of cyber-physical production systems (Poliak et al., 2020), digital twins, constituting a digital duplicate of a physical asset or system, mirroring its features and connections to the factory setting, shape smart manufacturing. (Zheng and Sivabalan, 2020)

\section{Conceptual Framework and Literature Review}

Connectivity and data tracking in every part of the integrated manufacturing operations facilitate factory processes to be converted into data-driven evidence-based routines (Lăzăroiu et al., 2020), while tracing product fault sources, inspecting production coherent bottlenecks, and estimating subsequent resource demands. (Lu et al., 2020) A digital twin represents the technical mainstay for setting up cyber-physical production systems (Nica et al., 2021) in relation to Industry 4.0. (Liu et al., 2020a) A digital twin perpetually coexists with its physical system, configuring instantaneous high-fidelity replications of, and providing pervasive control over, it. (Zheng and Sivabalan, 2020) An essential component of cyber-physical systems, digital twins can supply decision support to improve engineering product lifecycle administration systems by use of remote monitoring and supervision, highfidelity replication, and solution generation performances. (Lim et al., 2020)

\section{Results and Discussion}

Big data capabilities can supply visibility into processes (Kovacova and Lăzăroiu, 2021; Nica and Stehel, 2021) and furthers the forecasting of future requirements in a digital twin cyberspace. State alterations in a physical object can be determined by sensors (Popescu et al., 2020; Throne and Lăzăroiu, 2020) and communicated to its digital twin in the data network. (Lu et al., 2020) A digital twin depends on the cyber-physical system infrastructure to carry out its purpose of reproducing the physical system by use of ultra-realistic mirrorings and implementing omnipresent supervision. (Zheng and Sivabalan, 2020) As digital twins are elaborate systems necessitating input intensive applications (Lăzăroiu et al., 2021; Popescu et al., 2021), a uniform data stream should be enabled between physical assets and 
their cyber-duplicates. (Lim et al., 2020) Digital twin can be instrumental in hampering energy-related mismanagement by supplying the components necessitated for the service constitution of the technical functionalities determined for the improvement of process and systematic coherence. (Park et al., 2020) Digital twins are pivotal in the concatenated design and production as a result of multi-dimension and instantaneousness. (Zhou et al., 2021) The assimilation of the cutting-edge technologies that will assist digital twins in predicting precise behavior (e.g., data integration and machine learning) is critical across digitalized factories. (Mourtzis, 2020) (Tables 1-5)

Table 1. Realizing the full promise of digital twins may require integrating systems and data across entire organizational ecosystems. (\%, relevance)

\begin{tabular}{|c|c|}
\hline $\begin{array}{c}\text { Digital twins would enable companies to collaborate virtually, intake sensor data and } \\
\text { simulate conditions quickly, understand what-if scenarios clearly, predict results more } \\
\text { accurately, and output instructions to manipulate the physical world. }\end{array}$ & 97 \\
\hline $\begin{array}{c}\text { Digital twins can optimize processes, make data-driven decision in real time, and design } \\
\text { new products, services, and business models. }\end{array}$ & 96 \\
\hline $\begin{array}{c}\text { Digital twins can represent a new product's engineering drawings and dimensions, or } \\
\text { represent all the subcomponents and corresponding lineage in the broader supply chain } \\
\text { from the design table all the way to the consumer. They may also take a physical } \\
\text { representation of equipment on the production floor. }\end{array}$ & 95 \\
\hline $\begin{array}{c}\text { The simulation captures how the equipment operates, how engineers maintain it, } \\
\text { or even how the goods this equipment manufactures relates to customers. }\end{array}$ & 93 \\
\hline $\begin{array}{c}\text { Digital twin capabilities can streamline the design process and eliminate many aspects of } \\
\text { prototype testing. }\end{array}$ & 92 \\
\hline $\begin{array}{c}\text { Digital twins are poised to transform the way companies perform predictive maintenance } \\
\text { of products and machinery in the field. Sensors embedded in the machines feed } \\
\text { performance data into a digital twin in real time, making it possible not only to identify } \\
\text { and address malfunctions before they happen but to tailor service and maintenance plans to } \\
\text { better meet unique customer needs. }\end{array}$ & 90 \\
\hline $\begin{array}{c}\text { Digital twins can help optimize supply chains, distribution and fulfillment operations, and } \\
\text { even the individual performance of the workers involved in each. }\end{array}$ & 89 \\
\hline $\begin{array}{c}\text { For logistics, manufacturing, and supply chains, digital twins combined with machine } \\
\text { learning and advanced network connectivity such as 5G will increasingly track, monitor, } \\
\text { route, and optimize the flow of goods throughout factories. }\end{array}$ & 88 \\
\hline $\begin{array}{c}\text { Connecting a digital twin to embedded sensors and using it for financial analysis and } \\
\text { projections enables better refinement and optimization of projections, pricing, and upsell } \\
\text { opportunities. }\end{array}$ & 87 \\
\hline
\end{tabular}

Source: Deloitte; our survey among 3,900 individuals conducted February 2021.

Table 2. Organizations in multiple sectors are developing, testing, and utilizing digital twins within their operations. $(\%$, relevance $)$

\begin{tabular}{|c|c|}
\hline $\begin{array}{c}\text { Using simulation and machine learning, the digital twin forecasts } \\
\text { the probability of component failure. }\end{array}$ & 96 \\
\hline $\begin{array}{c}\text { By providing a comprehensive real-time view of factory performance, the digital twin helps } \\
\text { managers and staff to find improvement opportunities and react quickly to issues as they } \\
\text { arise. }\end{array}$ & 95 \\
\hline $\begin{array}{c}\text { Digitalizing the physical environment and visualizing its digital twin enables actionable } \\
\text { insights and much faster decision-making. }\end{array}$ & 94 \\
\hline $\begin{array}{c}\text { Digital twins will empower the factory workforce, by providing dramatically improved } \\
\text { access to data and information. }\end{array}$ & 93 \\
\hline Digital twins enable efficient maintenance strategies and remote diagnosis and repair. & 92 \\
\hline $\begin{array}{c}\text { Digital twins will enable more products to be configured and customized } \\
\text { to match the specific requirements of individual customers. }\end{array}$ & 90 \\
\hline Digital twins can help companies maximize the potential value of & 89 \\
\hline
\end{tabular}


end-of-life equipment by helping them to identify the exact type and content of equipment.

By offering a more complete view of the performance of products across their lifecycle,

digital twins will allow companies to take a more holistic, end-to-end approach to the

management of those products.

Sources: DHL; our survey among 3,900 individuals conducted February 2021.

Table 3. What components do you think are necessary for a digital twin? Select all that apply. (\%)

\begin{tabular}{|c|c|}
\hline Physical asset & 78 \\
\hline Live data set & 65 \\
\hline Offline data set & 56 \\
\hline 3D representation & 53 \\
\hline Real-time simulation & 51 \\
\hline Trend analysis of historical data & 50 \\
\hline Prediction of future events & 45 \\
\hline 2D graphic representation & 41 \\
\hline Unique physical asset & 33 \\
\hline
\end{tabular}

Sources: Catapult; ZDNet; our survey among 3,900 individuals conducted February 2021.

Table 4. Digital twin adoption benefits. Select all that apply. (\%)

\begin{tabular}{|c|c|}
\hline Increase business agility & 88 \\
\hline More first-time right products & 87 \\
\hline Better collaboration across engineering functions & 86 \\
\hline More consistently applying product knowledge during development & 85 \\
\hline Address complexity & 83 \\
\hline Better understand the product & 82 \\
\hline
\end{tabular}

Sources: Altair; our survey among 3,900 individuals conducted February 2021.

Table 5. Deployment of digital twin capabilities has accelerated due to a number of factors. ( $\%$, relevance)

\begin{tabular}{|c|c|c|}
\hline Simulation & $\begin{array}{l}\text { The tools for building digital twins are growing in power and } \\
\text { sophistication. It is now possible to design complex what-if simulations, } \\
\text { backtrack from detected real-world conditions, and perform millions of } \\
\text { simulation processes without overwhelming systems. With the number } \\
\text { of vendors increasing, the range of options continues to grow and } \\
\text { expand. Machine learning functionality is enhancing the depth and } \\
\text { usefulness of insights. }\end{array}$ & 96 \\
\hline $\begin{array}{l}\text { New sources of } \\
\text { data }\end{array}$ & $\begin{array}{l}\text { Data from real-time asset monitoring technologies such as LIDAR and } \\
\text { FLIR can now be incorporated into digital twin simulations. IoT sensors } \\
\text { embedded in machinery or throughout supply chains can feed } \\
\text { operational data directly into simulations, enabling continuous real-time } \\
\text { monitoring. }\end{array}$ & 94 \\
\hline Interoperability & $\begin{array}{c}\text { Much of the ability to integrate digital technology with the real world } \\
\text { can be attributed to enhanced industry standards for communications } \\
\text { between IoT sensors, operational technology hardware, and vendor } \\
\text { efforts to integrate with diverse platforms. }\end{array}$ & 93 \\
\hline Visualization & $\begin{array}{l}\text { The sheer volume of data required to create digital twin simulations can } \\
\text { complicate analysis and make efforts to gain meaningful insights } \\
\text { challenging. Advanced data visualization can help meet this challenge by } \\
\text { filtering and distilling information in real time. The latest data } \\
\text { visualization tools go far beyond basic dashboards and standard } \\
\text { visualization capabilities to include interactive 3D, VR and AR-based } \\
\text { visualizations, AI-enabled visualizations, and real-time streaming. }\end{array}$ & 92 \\
\hline Instrumentation & $\begin{array}{l}\text { IoT sensors, both embedded and external, are becoming smaller, more } \\
\text { accurate, cheaper, and more powerful. With improvements in networking }\end{array}$ & 90 \\
\hline
\end{tabular}




\begin{tabular}{|c|c|c|}
\hline & $\begin{array}{l}\text { technology and security, traditional control systems can be leveraged to } \\
\text { have more granular, timely, and accurate information on real-world } \\
\text { conditions to integrate with the virtual models. }\end{array}$ & \\
\hline Platform & $\begin{array}{l}\text { Increased availability of and access to powerful and inexpensive } \\
\text { computing power, network, and storage are key enablers of digital twins. }\end{array}$ & 89 \\
\hline
\end{tabular}

Sources: Deloitte; our survey among 3,900 individuals conducted February 2021.

Digital twins can reinforce coherent supervision and decision making with decreased incongruences by use of vertical integration and horizontal synchronization. (Park et al., 2020) Digital twins can attain hardware-in-the-loop replication of both physical tools and virtual model. (Liu et al., 2020b) Digital twin models represent virtual replicas of physical objects or systems, and their applications direct attention to smart manufacturing systems. (Sun et al., 2020) A digital twin-driven manufacturing management system can progressively replicate and upgrade production operations in manufacturing and attain instantaneous harmonization, high fidelity, and real-virtual merging in cyber-physical engineering. (Ma et al., 2020) Digital twin can enable networking between the physical and the cyber realms and carry out smart manufacturing. (Wang et al., 2020) (Tables 6-9)

Table 6. Digital twins can be used in different ways to add value to a product, process, user, or organization. (\%, relevance)

\begin{tabular}{|c|c|}
\hline $\begin{array}{c}\text { Digital twins are creating new value, helping companies to design, visualize, monitor, } \\
\text { manage, and maintain their assets more effectively. }\end{array}$ & 98 \\
\hline $\begin{array}{l}\text { Digital twins will extend the benefits of IoT already being applied today, bringing deeper } \\
\text { insight into the planning, design, operation, and optimization of supply chains, from } \\
\text { individual assets and shipments to entire global supply networks. }\end{array}$ & 97 \\
\hline $\begin{array}{l}\text { IoT technologies make digital twins possible because it is now technically } \\
\text { and economically feasible to collect large volumes of data from a wider range of objects. }\end{array}$ & 96 \\
\hline $\begin{array}{c}\text { Digital twin is often an ideal way to structure, access, and analyze complex product- } \\
\text { related data. }\end{array}$ & 95 \\
\hline $\begin{array}{l}\text { Digital twins rely on a host of underlying technologies that are only } \\
\text { now reaching the point where they can be applied reliably, cost effectively, and at scale. }\end{array}$ & 94 \\
\hline $\begin{array}{c}\text { Developing, maintaining, and using digital twins is a compute- and storage-intensive } \\
\text { endeavor. }\end{array}$ & 94 \\
\hline $\begin{array}{l}\text { Virtual reality enables the creation of entirely new environments to render digital twins in } \\
\text { a highly immersive way, creating the richest consumption of and interaction with the } \\
\text { information. }\end{array}$ & 93 \\
\hline $\begin{array}{l}\text { Digital twins that incorporate simulation technologies can provide data that is impossible } \\
\text { to measure directly on the physical object. }\end{array}$ & 92 \\
\hline $\begin{array}{l}\text { Digital twins can include diagnostic systems that use measured or derived data to suggest } \\
\text { the most probable root causes of specific states or behaviors. }\end{array}$ & 92 \\
\hline $\begin{array}{l}\text { Digital twins will play a significant role in the development of future smart factories } \\
\text { capable of making autonomous decisions about what to make, when and how, in order to } \\
\text { maximize customer satisfaction - and profitability. }\end{array}$ & 91 \\
\hline $\begin{array}{l}\text { Digital twins can be used to automate tedious error-prone activities such as inspections, } \\
\text { testing, analysis, and reporting. }\end{array}$ & 90 \\
\hline $\begin{array}{l}\text { Digital twins allow manufacturers to monitor, diagnose, and optimize their assets } \\
\text { remotely, helping to improve availability and reduce service costs. }\end{array}$ & 89 \\
\hline $\begin{array}{l}\text { Digital twins are now used throughout the full product lifecycle, with a product's twin } \\
\text { emerging during the development process and evolving to support different business } \\
\text { needs as a product progresses through design, manufacturing, launch, distribution, } \\
\text { operation, servicing, and decommissioning. }\end{array}$ & 89 \\
\hline $\begin{array}{l}\text { If the organization manufactures a new digital twin with every product it makes, each } \\
\text { model will incorporate data on the specific components and materials used in the product, } \\
\text { configuration options selected by end customers, and process conditions experienced } \\
\text { during production. }\end{array}$ & 88 \\
\hline
\end{tabular}




\begin{tabular}{|c|c|}
\hline $\begin{array}{c}\text { Digital twins support the entire lifecycle, from design time, through construction and } \\
\text { commissioning, all the way through to operations. }\end{array}$ & 88 \\
\hline $\begin{array}{c}\text { Once the product passes into the hands of the end-user, its digital twin continues to } \\
\text { accumulate data on its performance and operating conditions. }\end{array}$ & 87 \\
\hline
\end{tabular}

Sources: DHL; our survey among 3,900 individuals conducted February 2021.

Table 7. Digital twins are powerful technologies to drive innovation and performance. (\%, relevance)

\begin{tabular}{|c|c|}
\hline $\begin{array}{c}\text { Digital twin technology integrate AI, software analytics and machine learning data to } \\
\text { create a digital simulation models that update and change as their physical counterparts' } \\
\text { change. }\end{array}$ & 95 \\
\hline $\begin{array}{l}\text { Digital twin contains sensors that collect data to represent real time data of the physical } \\
\text { asset. } \\
\text { The sensor data is collected, analyzed and used in predictive analytics by the digital twin } \\
\text { to optimize the product's performance via a maintenance regime. }\end{array}$ & 94 \\
\hline $\begin{array}{l}\text { Digital twin technology help companies improve the customer experience by better } \\
\text { understanding customer needs, develop enhancements to existing products, operations, } \\
\text { and services, and can even help drive the innovation of new business. }\end{array}$ & 93 \\
\hline $\begin{array}{l}\text { The main benefit of digital twin is to provide an integrated outlook of any project to any } \\
\text { user at any point of the product lifetime. }\end{array}$ & 91 \\
\hline $\begin{array}{c}\text { Digital twin technology eliminates the guesswork from determining } \\
\text { the best course of action to service critical physical assets. }\end{array}$ & 90 \\
\hline $\begin{array}{l}\text { By directly creating a digital twin of the customer facing applications, } \\
\text { businesses can get feedback that boost the services directly offered to customers. }\end{array}$ & 89 \\
\hline $\begin{array}{l}\text { A digital twin helps to determine the optimal set of actions that can help maximize } \\
\text { some of the key performance metrics, and also provide forecasts for long-term planning. }\end{array}$ & 88 \\
\hline $\begin{array}{c}\text { A digital twin is capable of analyzing performance data collected over time and under } \\
\text { different conditions. }\end{array}$ & 87 \\
\hline $\begin{array}{c}\text { With a digital twin, businesses can integrate the insights generated in a system, allow } \\
\text { visibility into current and future machine states, and trigger } \\
\text { appropriate remedial business workflows. }\end{array}$ & 86 \\
\hline
\end{tabular}

Sources: GAVS; our survey among 3,900 individuals conducted February 2021.

Table 8. In which areas are digital twins already used within your company? Select all that apply. (\%)

\begin{tabular}{|c|c|}
\hline Product development twin & 42 \\
\hline Production and supply chain twin & 33 \\
\hline Operational asset twin & 28 \\
\hline Product lifecycle twin & 24 \\
\hline Not in use & 33 \\
\hline
\end{tabular}

Sources: PwC; our survey among 3,900 individuals conducted February 2021.

Table 9 In which stages of the product life cycle do you see the digital twin offering greatest value? Select all that apply. (\%)

\begin{tabular}{|c|c|}
\hline Maintenance, repair, and operations & 84 \\
\hline Manufacturing & 80 \\
\hline Simulation & 74 \\
\hline Quality control & 71 \\
\hline Design & 68 \\
\hline Training & 63 \\
\hline Assembly & 58 \\
\hline Customization & 45 \\
\hline Stakeholder engagement & 42 \\
\hline Disassembly & 38 \\
\hline Sales and marketing & 31 \\
\hline
\end{tabular}


Sources: Catapult; ZDNet; our survey among 3,900 individuals conducted February 2021.

Operators harness digital twin data and cyber-designs to optimize preventive maintenance, launch cutting-edge business models (Lyons and Lăzăroiu, 2020), enhance product development, and upgrade the sustainability and efficiency of manufactured items. Digital twin configures wide-ranging digital patterns of industrial settings furthering networking between the digital model and the physical entity to facilitate instantaneous engineering decisions. (Nguyen et al., 2021) Industry 4.0-based manufacturing systems interconnect virtual realms with physical ones, articulating smart factory advancement. Digital twin-based Internet of Things systems fortify virtual and real synthesis, generating closed-loop recurrent upgrading in cyber-physical smart manufacturing. (Wang and Luo, 2021)

\section{Conclusions and Implications}

The juxtaposition of the digital and physical realms results in smart decisions throughout manufacturing operations, consequently developing a data-driven smart production environment. A manufacturing asset can be networked and detached by the data network by use of its digital twin. (Lu et al., 2020) A digital twin is an elaborate digital object necessitating massive volumes of data, with visualizing and rendering performance, computational capacity, and intelligence. (Zheng and Sivabalan, 2020) Assimilating a smart agent across the industrial platforms additionally increases the harnessing of the system-level digital twin: groundbreaking supervision algorithms are regulated and tested upfront before being put into service to the physical realm for implementation. (Xia et al., 2020) A production unit-level digital twin facilitates process and systematic productivity improvement for sustainable and smart manufacturing. (Park et al., 2020)

\section{References}

1. Kovacova, M., \& Lăzăroiu, G. (2021). Sustainable organizational performance, cyberphysical production networks, and deep learning-assisted smart process planning in Industry 4.0-based manufacturing systems. Economics, Management, and Financial Markets, 16(3), 41-54.

2. Lăzăroiu, G., Machová, V., \& Kucera, J. (2020). Connected and autonomous vehicle mobility: Socially disruptive technologies, networked transport systems, and big data algorithmic analytics. Contemporary Readings in Law and Social Justice, 12(2), 61-69.

3. Lăzăroiu, G., Kliestik, T., and Novak, A. (2021). Internet of Things smart devices, industrial artificial intelligence, and real-time sensor networks in sustainable cyberphysical production systems. Journal of Self-Governance and Management Economics, 9(1), 20-30.

4. Lim, K. Y. H., Zheng, P., Chen, C.-H., \& Huang, L. (2020). A digital twin-enhanced system for engineering product family design and optimization. Journal of Manufacturing Systems, 57, 82-93.

5. Liu, C., Jiang, P., \& Jiang, W. (2020a). Web-based digital twin modeling and remote control of cyber-physical production systems. Robotics and Computer-Integrated Manufacturing, 64, 101956. 
6. Liu, Q., Leng, J., Yan, D., Zhang, D., Wei, L., Yu, A., et al. (2020b). Digital twin-based designing of the configuration, motion, control, and optimization model of a flow-type smart manufacturing system. Journal of Manufacturing Systems.

7. Lu, Y., Liu, C., Wang, K. I., Huang, H., \& Xu, X. (2020). Digital twin-driven smart manufacturing: Connotation, reference model, applications and research issues. Robotics and Computer-Integrated Manufacturing, 61, 101837.

8. Lyons, N., and Lăzăroiu, G. (2020). Addressing the COVID-19 crisis by harnessing Internet of Things sensors and machine learning algorithms in data-driven smart sustainable cities. Geopolitics, History, and International Relations, 12(2), 65-71.

9. Ma, J., Chen, H., Zhang, Y., Guo, H., Ren, Y., Mo, R., et al. (2020). A digital twindriven production management system for production workshop. The International Journal of Advanced Manufacturing Technology, 110, 1385-1397.

10. Mourtzis, D. (2020). Simulation in the design and operation of manufacturing systems: State of the art and new trends. International Journal of Production Research, 58(7), 1927-1949.

11. Nica, E., and Stehel, V. (2021). Internet of Things sensing networks, artificial intelligence-based decision-making algorithms, and real-time process monitoring in sustainable Industry 4.0. Journal of Self-Governance and Management Economics, 9(3), $35-47$.

12. Nica, E., Stan, C. I., Luțan (Petre), A. G., and Oașa (Geambazi), R.-Ș. (2021). Internet of Things-based real-time production logistics, sustainable industrial value creation, and artificial intelligence-driven big data analytics in cyber-physical smart manufacturing systems. Economics, Management, and Financial Markets, 16(1), 52-62.

13. Nguyen, H. X., Trestian, R., To, D., \& Tatipamula, M. (2021). Digital twin for 5G and beyond. IEEE Communications Magazine, 59(2), 10-15.

14. Park, K. T., Lee, D., \& Noh, S. D. (2020). Operation procedures of a work-center-level digital twin for sustainable and smart manufacturing. International Journal of Precision Engineering and Manufacturing-Green Technology, 7, 791-814.

15. Poliak, M., Baker, A., Konecny, V., \& Nica, E. (2020). Regulatory and governance mechanisms for self-driving cars: Social equity benefits and machine learning-based ethical judgments. Contemporary Readings in Law and Social Justice, 12(1), 58-64.

16. Popescu, G. H., Valaskova, K., \& Majerova, J. (2020). Real-time sensor networks, advanced robotics, and product decision-making information systems in data-driven sustainable smart manufacturing. Economics, Management, and Financial Markets, 15(4), 29-38.

17. Popescu, G. H., Petreanu, S., Alexandru, B., \& Corpodean, H. (2021). Internet of Thingsbased Real-Time Production Logistics, Cyber-Physical Process Monitoring Systems, and Industrial Artificial Intelligence in Sustainable Smart Manufacturing. Journal of Self-Governance and Management Economics, 9(2), 52-62.

18. Scott, R., Poliak, M., Vrbka, J., \& Nica, E. (2020). COVID-19 response and recovery in smart sustainable city governance and management: Data-driven Internet of Things systems and machine learning-based analytics. Geopolitics, History, and International Relations, 12(2), 16-22.

19. Sun, J., Tian, Z., Fu, Y., Geng, J., \& Liu, C. (2021). Digital twins in human understanding: A deep learning-based method to recognize personality traits. International Journal of Computer Integrated Manufacturing, 34(7/8), 860-873. 
20. Throne, O., \& Lăzăroiu, G. (2020). Internet of Things-enabled sustainability, industrial big data analytics, and deep learning-assisted smart process planning in cyber-physical manufacturing systems. Economics, Management, and Financial Markets, 15(4), 49-58.

21. Wang, K. J., Lee, T. L., \& Hsu, Y. (2020). Revolution on digital twin technology - A patent research approach. The International Journal of Advanced Manufacturing Technology, 107, 4687-4704.

22. Wang, P., \& Luo, M. (2021). A digital twin-based big data virtual and real fusion learning reference framework supported by industrial internet towards smart manufacturing. Journal of Manufacturing Systems, 58(A), 16-32.

23. Xia, K., Sacco, C., Kirkpatrick, M., Saidy, C., Nguyen, L., Kircaliali, A., et al. (2021). A digital twin to train deep reinforcement learning agent for smart manufacturing plants: Environment, interfaces and intelligence. Journal of Manufacturing Systems, 58(B), 210-230.

24. Zheng, P., \& Sivabalan, A. S. (2020). A generic tri-model-based approach for productlevel digital twin development in a smart manufacturing environment. Robotics and Computer-Integrated Manufacturing, 64, 101958.

25. Zhou, Y., Xing, T., Song, Y., Li, Y., Zhu, X., Li, G., et al. (2021). Digital-twin-driven geometric optimization of centrifugal impeller with free-form blades for five-axis flank milling. Journal of Manufacturing Systems, 58(B), 22-35. 